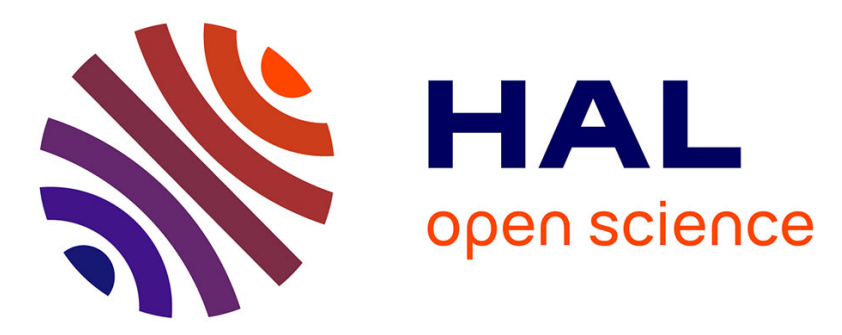

\title{
Reaction F + C2H4: Rate Constant and Yields of the Reaction Products as a Function of Temperature over 298-950 K
}

Yuri Bedjanian

\section{- To cite this version:}

Yuri Bedjanian. Reaction $\mathrm{F}+\mathrm{C} 2 \mathrm{H} 4$ : Rate Constant and Yields of the Reaction Products as a Function of Temperature over 298-950 K. Journal of Physical Chemistry A, 2018, 122 (12), pp.31563162. 10.1021/acs.jpca.8b01371 . hal-02118005

\section{HAL Id: hal-02118005 \\ https://hal.science/hal-02118005}

Submitted on 14 Jan 2022

HAL is a multi-disciplinary open access archive for the deposit and dissemination of scientific research documents, whether they are published or not. The documents may come from teaching and research institutions in France or abroad, or from public or private research centers.
L'archive ouverte pluridisciplinaire HAL, est destinée au dépôt et à la diffusion de documents scientifiques de niveau recherche, publiés ou non, émanant des établissements d'enseignement et de recherche français ou étrangers, des laboratoires publics ou privés. 
Reaction $\mathrm{F}+\mathrm{C}_{2} \mathrm{H}_{4}$ : Rate Constant and Yields of the Reaction Products as a Function of Temperature over 298 - $950 \mathrm{~K}$

\author{
Yuri Bedjanian* \\ Institut de Combustion, Aérothermique, Réactivité et Environnement (ICARE), CNRS \\ 45071 Orléans Cedex 2, France
}

*Corresponding author: Tel.: +33 238255474, Fax: +33 238696004, e-mail: yuri.bedjanian@cnrs-orleans.fr 


\section{ABSTRACT}

The kinetics and products of the reaction of $\mathrm{F}+\mathrm{C}_{2} \mathrm{H}_{4} \rightarrow$ products (1) have been studied in a discharge flow reactor combined with an electron impact ionization mass spectrometer at nearly 2 Torr total pressure of helium in the temperature range $298-950 \mathrm{~K}$. The total rate constant of the reaction, $k_{1}=(1.78 \pm 0.30) \times 10^{-10} \mathrm{~cm}^{3}$ molecule $\mathrm{s}^{-1}$, determined under pseudofirst order conditions, monitoring the kinetics of F-atom consumption in excess of $\mathrm{C}_{2} \mathrm{H}_{4}$, was found to be temperature independent in the temperature range used. $\mathrm{H}, \mathrm{C}_{2} \mathrm{H}_{3} \mathrm{~F}$ and $\mathrm{HF}$ were identified as the reaction products. Absolute measurements of the yields of these species allowed to determine the branching ratios, $k_{1 \mathrm{~b}} / k_{1}=(0.73 \pm 0.07) \exp (-(425 \pm 45) / \mathrm{T})$ and $k_{1 \mathrm{a}} / k_{1}$ $=1-(0.73 \pm 0.07) \exp (-(425 \pm 45) / \mathrm{T})$ and partial rate constants for addition-elimination $(\mathrm{H}+$ $\mathrm{C}_{2} \mathrm{H}_{3} \mathrm{~F}(1 \mathrm{a})$ ) and $\mathrm{H}$-atom abstraction $\left(\mathrm{HF}+\mathrm{C}_{2} \mathrm{H}_{3}(1 \mathrm{~b})\right)$ pathways of the title reaction: $k_{1 \mathrm{a}}=$ $(0.80 \pm 0.07) \times 10^{-10} \exp (189 \pm 37 / \mathrm{T})$ and $k_{1 \mathrm{~b}}=(1.26 \pm 0.13) \times 10^{-10} \exp (-414 \pm 45 / \mathrm{T})$ $\mathrm{cm}^{3}$ molecule $\mathrm{s}^{-1}$ at $\mathrm{T}=298-950 \mathrm{~K}$ and with $2 \sigma$ quoted uncertainties. The overall reaction rate constant can be adequately described by both the temperature independent value and as a sum of $k_{1 \mathrm{a}}$ and $k_{1 \mathrm{~b}}$. The kinetic and mechanistic data from the present study are discussed in comparison with previous absolute and relative measurements and theoretical calculations. 


\section{INTRODUCTION}

Multichannel reactions of fluorine atom with alkenes represent an interesting subject for experimental and theoretical investigations and were quite extensively studied over the past few decades. In particular, it was shown that these reactions proceed both through direct abstraction of hydrogen atom ${ }^{1-2}$ and addition of $\mathrm{F}$-atom to the double bond of alkene, leading to formation of a long-lived intermediate complex, ${ }^{1,3-9}$ which can be stabilized to form adductradical or decompose to the reaction products.

However, despite the great interest to these reactions and a large number of studies dedicated, quantitative kinetic (rate constants) and mechanistic (branching ratios for different reaction channels) data on these reactions, surprisingly, remain very limited. Thus, the rate constant of the F-atom reaction with the simplest alkene, ethylene, was determined only once and just at three temperatures, 202, 236 and $298 \mathrm{~K} .{ }^{10-11}$ Absolute measurements of the yields of the products of this multichannel reaction were carried out in two studies, and only with one of the reaction products $\left(\mathrm{C}_{2} \mathrm{H}_{3} \mathrm{~F}\right)$ and in a limited temperature range. ${ }^{11-12}$

In the present work, we report the results of an experimental study of the reaction of $\mathrm{F}$ atom with $\mathrm{C}_{2} \mathrm{H}_{4}$ over a wide temperature range (from room temperature to $950 \mathrm{~K}$ ), including temperature dependence of the total rate constant and the branching ratios for two main (at low pressure) reactive channels:

$$
\begin{aligned}
\mathrm{F}+\mathrm{C}_{2} \mathrm{H}_{4} & \rightarrow \mathrm{H}+\mathrm{C}_{2} \mathrm{H}_{3} \mathrm{~F} & \Delta_{\mathrm{r}} H^{\circ}=-52.6 \mathrm{~kJ} \mathrm{~mol}^{-1} \\
& \rightarrow \mathrm{HF}+\mathrm{C}_{2} \mathrm{H}_{3} & \Delta_{\mathrm{r}} H^{\circ}=-109.7 \mathrm{~kJ} \mathrm{~mol}^{-1}
\end{aligned}
$$

The thermochemical data used for the calculations of $\Delta_{\mathrm{r}} H^{\circ}$ are from ref. 13 . 


\section{EXPERIMENTAL}

Experiments were carried out in a discharge flow reactor using a modulated molecular beam mass spectrometer with electron impact ionization as the detection method. The flow reactor operated in the temperature range $298-950 \mathrm{~K}$ and nearly 2 Torr total pressure of Helium and consisted of an electrically heated Quartz tube (45 cm length and $2.5 \mathrm{~cm}$ i.d.) with watercooled extremities (Figure S1, Supporting Information). ${ }^{14}$ Temperature in the reactor was measured with a $K$-type thermocouple positioned in the middle of the reactor in contact with its outer surface. Temperature gradients along the flow tube measured with a thermocouple inserted in the reactor through the movable injector was found to be less than $1 \%{ }^{14}$

$\mathrm{F}$ atoms were formed in the microwave discharge of $\mathrm{F}_{2} / \mathrm{He}$ mixtures. In order to reduce $\mathrm{F}$ atom reactions with glass surface inside the microwave cavity, a ceramic $\left(\mathrm{Al}_{2} \mathrm{O}_{3}\right)$ tube was inserted in this part of the injector. It was verified by mass spectrometry that more than $90 \%$ of $\mathrm{F}_{2}$ was dissociated in the microwave discharge. Fluorine atoms were detected at $\mathrm{m} / \mathrm{z}=$ 98/100 $\left(\mathrm{FBr}^{+}\right)$after being scavenged with an excess of $\mathrm{Br}_{2}$ (added in the end of the reactor 5 $\mathrm{cm}$ upstream of the sampling cone, see Figure S1):

$$
\mathrm{F}+\mathrm{Br}_{2} \rightarrow \mathrm{FBr}+\mathrm{Br}
$$

This reaction was also used for the determination of the absolute concentrations of $\mathrm{FBr}$ : concentration of $\mathrm{FBr}$ was determined from the consumed fraction of $\mathrm{Br}_{2},[\mathrm{FBr}]=\Delta\left[\mathrm{Br}_{2}\right]$. $\mathrm{HF}$ (product of reaction 1) and $\mathrm{HBr}$ (monitored in the study of the reaction products) were detected at $\mathrm{m} / \mathrm{z}=20\left(\mathrm{HF}^{+}\right)$and $80 / 82\left(\mathrm{HBr}^{+}\right)$, respectively. Their signals were absolutely calibrated relative to those of $\mathrm{FBr}$ upon titration of F-atoms with $\mathrm{Br}_{2} / \mathrm{H}_{2}$ mixture. First, Fatoms were titrated with $\mathrm{Br}_{2}$, and $[\mathrm{FBr}]_{0}$ corresponding to initial concentration of $\mathrm{F}$ was detected. Then $\mathrm{H}_{2}$ was added in the reactive system leading to decrease of $[\mathrm{FBr}]$ due to concurrent loss of F-atom in reaction

$$
\mathrm{F}+\mathrm{H}_{2} \rightarrow \mathrm{HF}+\mathrm{H}
$$


followed by reaction 4 , transforming $\mathrm{H}$-atoms to $\mathrm{HBr}$ :

$$
\mathrm{H}+\mathrm{Br}_{2} \rightarrow \mathrm{HBr}+\mathrm{Br}
$$

This procedure allowed to link the absolute concentrations of $\mathrm{HF}, \mathrm{HBr}$ and $\mathrm{FBr}$ as follows: $[\mathrm{HF}]=[\mathrm{HBr}]=\Delta[\mathrm{FBr}] \cdot \mathrm{C}_{2} \mathrm{H}_{4}$ was detected at its fragment peak at $\mathrm{m} / \mathrm{z}=26\left(\mathrm{C}_{2} \mathrm{H}_{2}{ }^{+}\right)$, the parent peak at $\mathrm{m} / \mathrm{z}=28$ being somewhat perturbed by unavoidable traces of molecular nitrogen. The absolute concentrations of $\mathrm{C}_{2} \mathrm{H}_{4}$ as well as of other stable species $\left(\mathrm{Br}_{2}, \mathrm{H}_{2}\right.$, $\left.\mathrm{C}_{2} \mathrm{H}_{3} \mathrm{~F}\right)$ in the reactor were calculated from their flow rates obtained from the measurements of the pressure drop of their mixtures in He stored in calibrated volume flasks.

The purities of the gases used were as follows: He $>99.9995 \%$ (Alphagaz), passed through liquid nitrogen trap; $\mathrm{C}_{2} \mathrm{H}_{4}>99.99 \%$ (Phillips); $\mathrm{H}_{2}>99.998 \%$ (Alphagaz); $\mathrm{Br}_{2}$ $>99.99 \%$ (Aldrich); $\mathrm{F}_{2}, 5 \%$ in helium (Alphagaz); $\mathrm{C}_{2} \mathrm{H}_{3} \mathrm{~F}, 98 \%$ (Apollo Scientific).

\section{RESULTS AND DISCUSSION}

3.1. Measurements of the Reaction Rate Constant. The rate constant of the title reaction was determined using both absolute method through monitoring the kinetics of $\mathrm{F}$ atom consumption in excess of $\mathrm{C}_{2} \mathrm{H}_{4}$, and relative rate method with the reaction of $\mathrm{F}$ atom with $\mathrm{Br}_{2}$ as a reference one.

3.1.1. Kinetics of F-atom consumption in excess of $\mathrm{C}_{2} \mathrm{H}_{4}$. In these experiments, carried out in excess of $\mathrm{C}_{2} \mathrm{H}_{4}$, the initial concentration of F-atoms was in the range (0.91.5) $\times 10^{11}$ molecule $\mathrm{cm}^{-3}$; the concentrations of $\mathrm{C}_{2} \mathrm{H}_{4}$ are shown in Table 1 . The flow velocity in the reactor was in the range (2750-3680) $\mathrm{cm} \mathrm{s}^{-1}$. Examples of pseudo-first order F-atom decays are shown in Figure $\mathrm{S} 2$ (Supporting Information). Consumption of $\mathrm{C}_{2} \mathrm{H}_{4}$ was negligible in most cases due to its sufficient excess over F atoms; however in a few kinetic runs it was observable (up to $15 \%$ ). In this case, the mean values of $\left[\mathrm{C}_{2} \mathrm{H}_{4}\right]$ over the reaction time of the F-atom kinetics were used for the calculations of the rate constant. 
Table 1. Reaction $\mathrm{F}+\mathrm{C}_{2} \mathrm{H}_{4}$ : Summary of the Absolute Measurements of the Rate Constant.

$\begin{array}{cccc}T(\mathrm{~K}) & \begin{array}{c}\text { number of kinetic } \\ \text { runs }\end{array} & \begin{array}{c}{\left[\mathrm{C}_{2} \mathrm{H}_{4}\right]} \\ \left(10^{12} \text { molecule } \mathrm{cm}^{-3}\right)\end{array} & \left(10^{-10} \mathrm{~cm}^{3}{ }^{a} \text { molecule }^{-1} \mathrm{~s}^{-1}\right) \\ 298 & 7 & 0.48-4.58 & 1.77 \\ 348 & 7 & 0.26-3.74 & 1.76 \\ 413 & 8 & 0.22-3.57 & 1.74 \\ 509 & 9 & 0.32-3.27 & 1.81 \\ 665 & 8 & 0.33-3.31 & 1.77 \\ 950 & 8 & 0.33-4.97 & 1.76 \\ { }^{a} \text { Typical uncertainty on } k_{1} \text { is nearly } 15 \% . & & \end{array}$

Figure 1 demonstrates the pseudo-first order rate constants, $k_{1}{ }^{\prime}=k_{1}\left[\mathrm{C}_{2} \mathrm{H}_{4}\right]+k_{\mathrm{w}}$, measured as a function of the concentration of $\mathrm{C}_{2} \mathrm{H}_{4}$ at $\mathrm{T}=298$ and $950 \mathrm{~K}$. Similar data were observed at other temperatures of the study (Figures S3 and S4, Supporting Information). All the measured values of $k_{1}{ }^{\prime}$ were corrected for axial and radial diffusion ${ }^{15}$ of fluorine atoms. The corrections on $k_{1}{ }^{\prime}$ were calculated using diffusion coefficient of $\mathrm{F}$ in $\mathrm{He}, D_{0}=614 \times$ $(\mathrm{T} / 298)^{1.75}$ Torr $\mathrm{cm}^{-2} \mathrm{~s}^{-1}$ (estimated with Fuller's method) ${ }^{16}$ and were, generally, less than $10 \%$. The slopes of the straight lines in Figures 1, S3 and S4 provide the values of $k_{1}$ at respective temperatures. All the results obtained for $k_{1}$ within the described approach at different temperatures are shown in Table 1 . The combined uncertainty on the measurements of the rate constants was estimated to be $\approx 15 \%$, including statistical error (within a few percent) and those on the measurements of the flows (5\%), pressure (3\%), temperature (1\%) and absolute concentration of $\mathrm{C}_{2} \mathrm{H}_{4}(\leq 10 \%)$. 


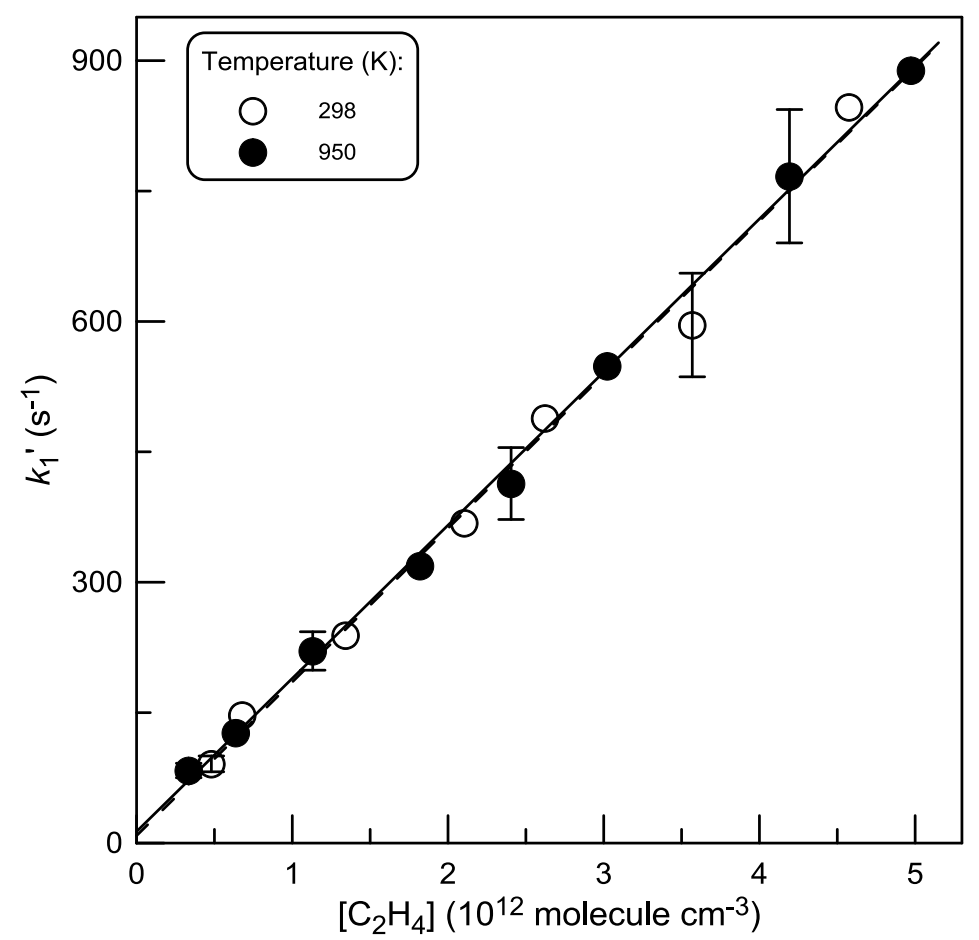

Figure 1. Reaction $\mathrm{F}+\mathrm{C}_{2} \mathrm{H}_{4}$ : pseudo-first order plots obtained from $\mathrm{F}$ - atom decays in excess of $\mathrm{C}_{2} \mathrm{H}_{4}$. Solid and dashed lines represent a linear fit to the experimental data at $\mathrm{T}=298$ and $950 \mathrm{~K}$, respectively. Error bars show a typical uncertainty of nearly $10 \%$ on the determination of $k_{1}{ }^{\prime}$.

3.1.2. Relative rate measurements. In these experiments, the rate constant of reaction 1 was determined at three temperatures, $\mathrm{T}=324,455$ and $782 \mathrm{~K}$, using a relative rate method with reaction of $\mathrm{F}$ atoms with $\mathrm{Br}_{2}$ as a reference one:

$$
\mathrm{F}+\mathrm{Br}_{2} \rightarrow \mathrm{FBr}+\mathrm{Br}
$$

Fast titration of the initial concentration of $\mathrm{F}$ atoms, $[\mathrm{F}]_{0}$, by a mixture of excess $\mathrm{C}_{2} \mathrm{H}_{4}$ and $\mathrm{Br}_{2}$ was performed, and the yield of $\mathrm{FBr}$ was measured as a function of the $\left[\mathrm{Br}_{2}\right] /\left[\mathrm{C}_{2} \mathrm{H}_{4}\right]$ ratio. The concentration of $\mathrm{FBr}$ formed is defined by the fraction of $[\mathrm{F}]_{0}$ reacting with $\mathrm{Br}_{2}$ in reaction 2:

$$
[\mathrm{FBr}]=\frac{k_{2}\left[\mathrm{Br}_{2}\right]}{k_{2}\left[\mathrm{Br}_{2}\right]+k_{1}\left[\mathrm{C}_{2} \mathrm{H}_{4}\right]} \times[\mathrm{F}]_{0}
$$

Rearrangement of this expression leads to:

$$
\frac{[\mathrm{F}]_{0}}{[\mathrm{FBr}]}-1=\frac{k_{1}\left[\mathrm{C}_{2} \mathrm{H}_{4}\right]}{k_{2}\left[\mathrm{Br}_{2}\right]}
$$

Thus $k_{1} / k_{2}$ could be obtained by plotting $\left([\mathrm{F}]_{0} /[\mathrm{FBr}]-1\right)$ as a function of the $\left[\mathrm{C}_{2} \mathrm{H}_{4}\right] /\left[\mathrm{Br}_{2}\right]$ ratio. It can be noted that this method did not need absolute calibration of the mass- 
spectrometric signals for $\mathrm{F}$ and $\mathrm{FBr}$ because the initial concentration of $\mathrm{F}$ atoms could be expressed as $\mathrm{FBr}$ signal in the absence of $\mathrm{C}_{2} \mathrm{H}_{4}$ in the reactor, when $\mathrm{F}$ is titrated with an excess of $\mathrm{Br}_{2}$. Thus, in the experiments, only the $\mathrm{FBr}$ signal was detected: first, in $\mathrm{C}_{2} \mathrm{H}_{4}$-free system, corresponding to $[\mathrm{F}]_{0}$, and then in the $\mathrm{Br}_{2}$ and $\mathrm{C}_{2} \mathrm{H}_{4}$-containing system, corresponding to the fraction of $[\mathrm{F}]_{0}$ reacted with $\mathrm{Br}_{2}$. Initial concentration of $\mathrm{F}$ atoms was $\sim 10^{12}$ molecule $\mathrm{cm}^{-3}$, concentrations of $\mathrm{C}_{2} \mathrm{H}_{4}$ and $\mathrm{Br}_{2}$ are shown in Table 2, reaction time was around $0.015 \mathrm{~s}$.

Table 2. Experimental Conditions and Results of the Relative Measurements of $k_{1}$.

\begin{tabular}{|c|c|c|c|c|c|c|}
\hline $\begin{array}{c}T \\
(\mathrm{~K})\end{array}$ & No./exp. ${ }^{a}$ & {$\left[\mathrm{C}_{2} \mathrm{H}_{4}\right]^{b}$} & {$\left[\mathrm{Br}_{2}\right]^{b}$} & {$\left[\mathrm{C}_{2} \mathrm{H}_{4}\right] /\left[\mathrm{Br}_{2}\right]$} & $k_{1} / k_{2}$ & $k_{1}^{c}$ \\
\hline 324 & 12 & $0.42-14.8$ & $2.55-3.12$ & $0.16-5.04$ & 0.722 & 1.77 \\
\hline 455 & 12 & $0.29-8.98$ & $1.85-2.14$ & $0.07-4.77$ & 0.694 & 1.84 \\
\hline 782 & 11 & $0.61-4.74$ & $1.59-1.73$ & $0.11-2.74$ & 0.725 & 1.77 \\
\hline
\end{tabular}

The observed experimental data are shown in Figures $2(\mathrm{~T}=324$ and 455K) and S5 $(\mathrm{T}=$ 782K, Supporting Information). According to equation (I), the slopes of the linear dependences in Figures 2 and S5 provide the values of $k_{1} / k_{2}$ at respective temperatures (Table 2 ). Final values of $k_{1}$, calculated with independent of temperature $k_{2}=(1.28 \pm 0.20) \times 10^{-10}$ $\mathrm{cm}^{3}$ molecule $\mathrm{s}^{-1}(\mathrm{~T}=299-940 \mathrm{~K})^{17}$ and presented in Table 2, are in excellent agreement with the absolute measurement of the rate constant. All the results obtained for $k_{1}$ are shown Figure 3. Based on the data from this work, the temperature independent value of

$$
k_{1}=(1.78 \pm 0.30) \times 10^{-10} \mathrm{~cm}^{3} \text { molecule }{ }^{-1} \mathrm{~s}^{-1},
$$

can be recommended for the rate constant of reaction 1 in the temperature range (298-950) $\mathrm{K}$ (continuous line in Figure 3). 


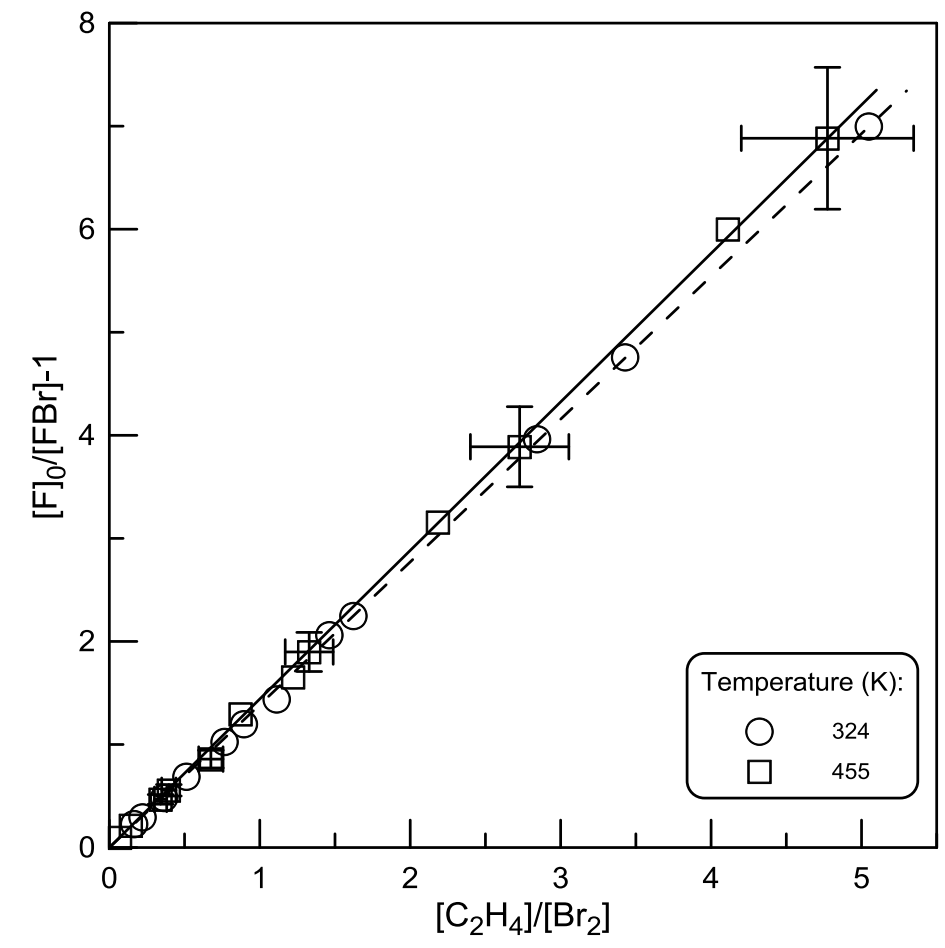

Figure 2. $\mathrm{FBr}$ yield from $\mathrm{F}$-atom titration with $\mathrm{Br}_{2}+\mathrm{C}_{2} \mathrm{H}_{4}$ mixtures at $\mathrm{T}=324$ and $455 \mathrm{~K}$. The horizontal and vertical error bars represent the estimated uncertainties (of nearly 10\%) on the respective values.

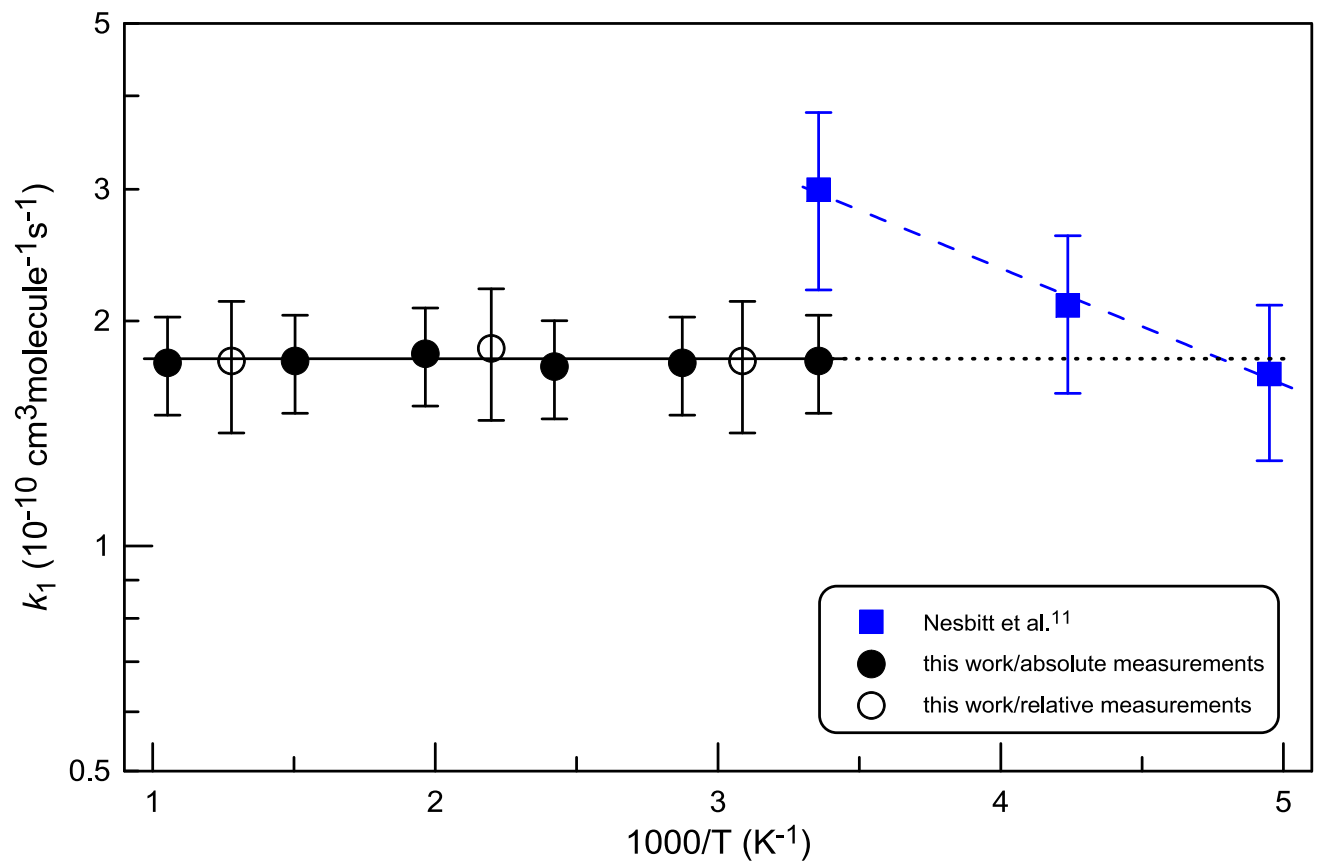

Figure 3. Reaction $\mathrm{F}+\mathrm{C}_{2} \mathrm{H}_{4}$ : summary of the experimental data on the temperature dependence of the reaction rate constant. 
3.2. Products of reaction 1. In a first series of experiments the yields of the reaction products, $\mathrm{C}_{2} \mathrm{H}_{3} \mathrm{~F}$ (channel 1a) and $\mathrm{HF}$ (channel 1b) were determined through the measurements of the consumed concentration of $\mathrm{F}$ atoms and formed concentrations of the reaction products. Reaction time was (0.012-0.016) s, initial concentrations of $\mathrm{F}$ atoms and $\mathrm{C}_{2} \mathrm{H}_{4}$ were $(0.1-3.3) \times 10^{12}$ and $(2.5-5.0) \times 10^{13}$ molecule $\mathrm{cm}^{-3}$, respectively. Under these experimental conditions, $F$ atoms were completely consumed in the reaction with $\mathrm{C}_{2} \mathrm{H}_{4}$. Example of the experimental data observed at $\mathrm{T}=298$ and $509 \mathrm{~K}$ is shown in Figure 4. Similar data observed at other temperatures of the study $(\mathrm{T}=348,414,663$ and $950 \mathrm{~K})$ are shown in Figures S6 and S7 (Supporting Information).

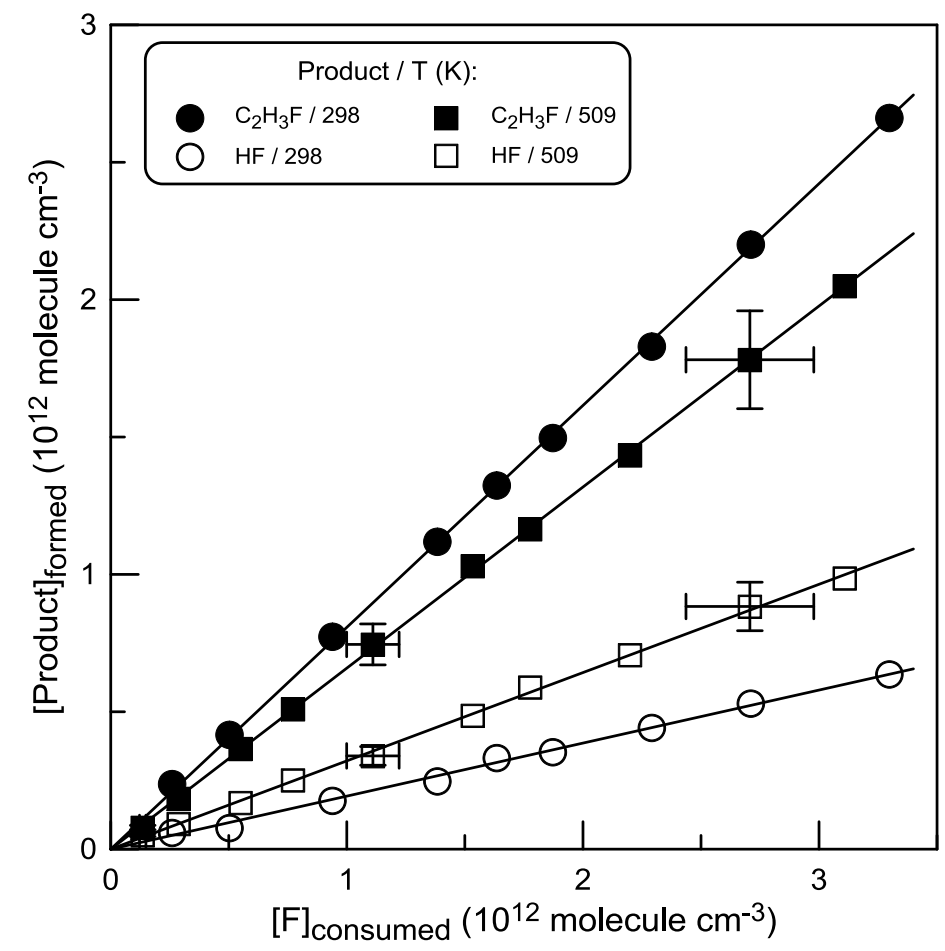

Figure 4. Reaction $\mathrm{F}+\mathrm{C}_{2} \mathrm{H}_{4}$ : concentrations of $\mathrm{C}_{2} \mathrm{H}_{3} \mathrm{~F}$ and $\mathrm{HF}$ formed in reaction 1 as a function of the consumed concentration of $\mathrm{F}$ atoms. Error bars correspond to typical $10 \%$ uncertainties on the determination of the absolute concentrations of the relevant species.

The slopes of the linear through origin fits to the experimental data in Figures 4, S6 and S7 provide the yields of $\mathrm{C}_{2} \mathrm{H}_{3} \mathrm{~F}$ and $\mathrm{HF}$ in reaction 1. All the results obtained in this way for the branching ratios, $k_{1 \mathrm{a}} / k_{1}$ and $k_{1 \mathrm{~b}} / k_{1}$, at different temperatures are shown in Table 3. Estimated systematic uncertainty on the measurements of $k_{1 \mathrm{a}} / k_{1}$ and $k_{1 \mathrm{~b}} / k_{1}$ is around $15 \%$ and is mainly 
due to the precision on the measurements of the absolute concentrations of the respective species.

Table 3. Summary of the Measurements of the Yields of the Products of Reaction $F+C_{2} H_{4}$.

\begin{tabular}{llccc} 
& \multicolumn{4}{c}{ yields of the reaction products ${ }^{a}$} \\
\cline { 2 - 4 } 298 & $\mathrm{H}$ & $\mathrm{C}_{2} \mathrm{H}_{3} \mathrm{~F}$ & $\mathrm{HF}$ & total $^{b}$ \\
324 & 0.807 & 0.192 & 0.999 \\
348 & & 0.199 & 0.999 \\
413 & 0.800 & 0.795 & 0.204 & 0.999 \\
454 & 0.726 & 0.245 & 0.971 \\
509 & & 0.268 & 1.000 \\
663 & 0.732 & 0.659 & 0.322 & 0.981 \\
776 & & 0.608 & 0.377 & 0.985 \\
950 & & 0.423 & 0.978 \\
${ }^{a}$ Uncertainty on the yields is nearly $15 \%{ }^{b}$ Sum of the yields of the reaction products.
\end{tabular}

In another series of experiments, the branching ratios for two channels of reaction 1 were determined through relative measurements of the yields of $\mathrm{H}$-atoms and $\mathrm{HF} . \mathrm{Br}_{2}\left(\approx 5 \times 10^{13}\right.$ molecule $\mathrm{cm}^{-3}$ ) being added in the end of the reactor, $\mathrm{F}$ atoms were titrated either with $\mathrm{H}_{2}$ $\left(5 \times 10^{13}\right.$ molecule $\left.\mathrm{cm}^{-3}\right)$ or $\mathrm{C}_{2} \mathrm{H}_{4}\left(\approx 10^{13}\right.$ molecule $\left.\mathrm{cm}^{-3}\right)$. Upon titration with $\mathrm{H}_{2}$ (reaction 3 followed by reaction 4),

$$
\begin{array}{ll}
\mathrm{F}+\mathrm{H}_{2} & \rightarrow \mathrm{HF}+\mathrm{H} \\
\mathrm{H}+\mathrm{Br}_{2} & \rightarrow \mathrm{HBr}+\mathrm{Br}
\end{array}
$$

$\mathrm{F}$ atoms were transformed to $\mathrm{HF}$ and $\mathrm{H}(\mathrm{HBr}):[\mathrm{F}]_{0}=[\mathrm{HF}]_{0}=[\mathrm{HBr}]_{0}$. Further, $\mathrm{H}_{2}$ was replaced with $\mathrm{C}_{2} \mathrm{H}_{4}$ and $[\mathrm{HF}]$ and $[\mathrm{H}]$ (detected as $\mathrm{HBr}$ ), formed in reaction 1, were measured. This method does not imply the measurements of the absolute concentrations of the species involved, as the yields of $\mathrm{H}$ and $\mathrm{HF}$ in reaction 1 can be calculated as $[\mathrm{HBr}] /[\mathrm{HBr}]_{0}$ and $[\mathrm{HF}] /[\mathrm{HF}]_{0}$, respectively. Reaction time in these experiments was nearly $4 \mathrm{~ms}$ and initial concentration of F-atoms was varied in the range $(0.21-1.69)$ and $(0.17-1.33) \times 10^{12}$ molecule $\mathrm{cm}^{-3}$ at $\mathrm{T}=454$ and $776 \mathrm{~K}$, respectively. Results of the measurements are shown in Figure 5. 
The slopes of the straight lines in Figure 5 provide the yields of $\mathrm{H}$ and $\mathrm{HF}$ at $\mathrm{T}=454$ and 776 $\mathrm{K}$ presented in Table 3 .

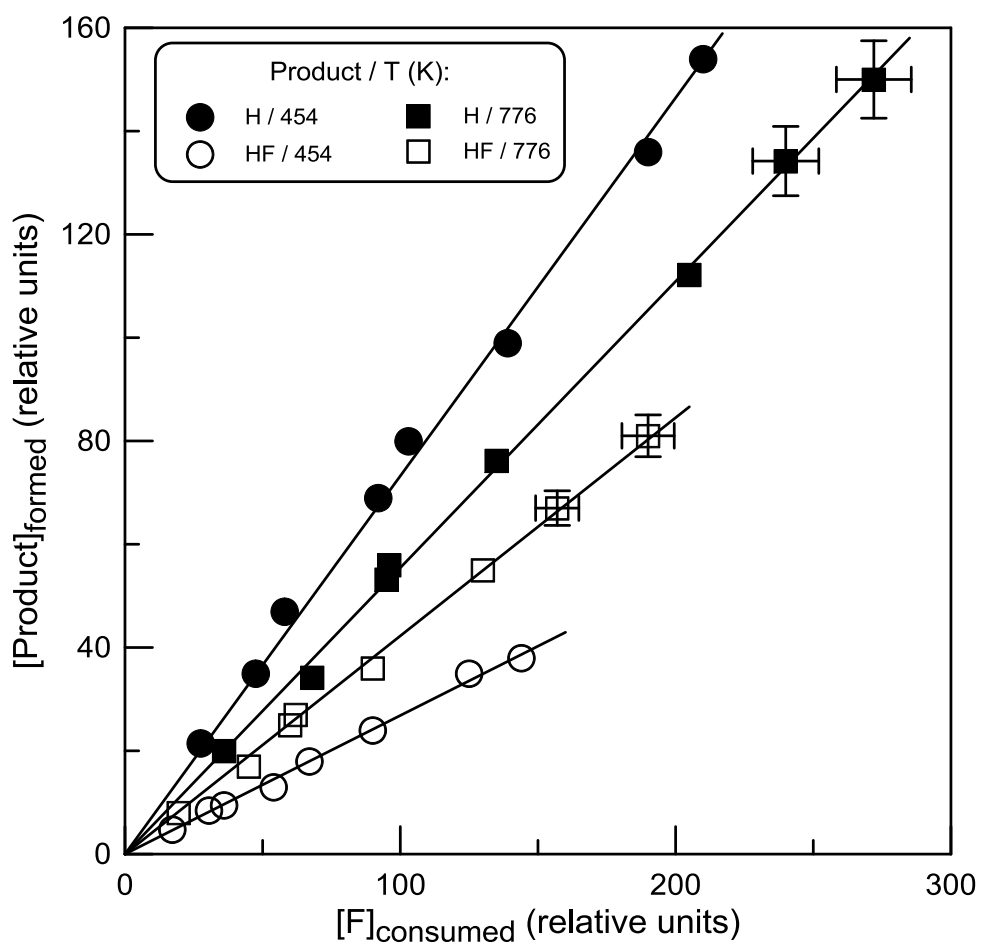

Figure 5. Reaction $\mathrm{F}+\mathrm{C}_{2} \mathrm{H}_{4}$ : concentrations of $\mathrm{H}$-atom and $\mathrm{HF}$ formed in reaction 1 as a function of the consumed concentration of $\mathrm{F}$ atoms. Error bars correspond to typical of nearly 5\% uncertainty on the determination of the relatives concentrations of the respective species.

Secondary reactions, potentially leading to hydrogen atom consumption or production in the reactive system used, can be analyzed. Hydrogen atoms produced in reaction 1 can be lost on the reactor surface and in a secondary reaction with excess reactant $\mathrm{C}_{2} \mathrm{H}_{4}$ :

$$
\begin{aligned}
& \mathrm{H}+\mathrm{C}_{2} \mathrm{H}_{4}(+\mathrm{M}) \rightarrow \mathrm{C}_{2} \mathrm{H}_{5}(+\mathrm{M}) \\
& \mathrm{H}+\mathrm{C}_{2} \mathrm{H}_{4} \rightarrow \mathrm{H}_{2}+\mathrm{C}_{2} \mathrm{H}_{3}
\end{aligned}
$$

Under experimental conditions of the present study, the abstraction channel $5 \mathrm{~b}$ is negligible and reaction is dominated by addition pathway $5 \mathrm{a}$ with a rate constant of nearly $10^{-13}$ $\mathrm{cm}^{3}$ molecule $\mathrm{s}^{-1} \cdot{ }^{-18}$ Considering the reaction time $(0.004 \mathrm{~s})$ and concentration of $\mathrm{C}_{2} \mathrm{H}_{4}\left(\approx 10^{13}\right.$ molecule $\mathrm{cm}^{-3}$ ) used in these experiments, the $\mathrm{H}$ atom consumption in reaction 5 can be neglected. Heterogeneous loss of $\mathrm{H}$ atoms also did not affect the results of the measurement, since (i) its rate is relatively low $\left(\leq 10 \mathrm{~s}^{-1}\right)$ and (ii) its possible impact on $\mathrm{H}$-atom 
concentration is similar in the presence of $\mathrm{H}_{2}$ (determination of the initial concentration) and $\mathrm{C}_{2} \mathrm{H}_{4}$ (determination of the concentration formed in reaction). Secondary production of hydrogen atoms in reaction of another reaction product, $\mathrm{C}_{2} \mathrm{H}_{3}$, with $\mathrm{C}_{2} \mathrm{H}_{4}$ can also be neglected under experimental conditions of the measurements:

$$
\begin{aligned}
& \mathrm{C}_{2} \mathrm{H}_{3}+\mathrm{C}_{2} \mathrm{H}_{4} \rightarrow \mathrm{H}+\mathrm{C}_{4} \mathrm{H}_{6} \\
& k_{6}=1.3 \times 10^{-13} \mathrm{~cm}^{3} \text { molecule } \mathrm{s}^{-1}(\mathrm{~T}=1100 \mathrm{~K})^{18}
\end{aligned}
$$

In contrast, the secondary reactions

$$
\begin{aligned}
& \mathrm{H}+\mathrm{C}_{2} \mathrm{H}_{3} \rightarrow \mathrm{H}_{2}+\mathrm{C}_{2} \mathrm{H}_{2} \\
& k_{7 \mathrm{a}}=7 \times 10^{-11} \mathrm{~cm}^{3} \text { molecule }^{-1} \mathrm{~s}^{-1}(\mathrm{~T}=300 \mathrm{~K})^{18} \text { and } \\
& \mathrm{H}+\mathrm{C}_{2} \mathrm{H}_{3}(+\mathrm{M}) \rightarrow \mathrm{C}_{2} \mathrm{H}_{4}(+\mathrm{M}) \\
& k_{7 \mathrm{~b}}=9.3 \times 10^{-11} \mathrm{~cm}^{3} \text { molecule } \mathrm{s}^{-1}(\mathrm{P}=2 \text { Torr, } \mathrm{T}=300 \mathrm{~K})^{18}
\end{aligned}
$$

are pretty rapid and could potentially affect the measured concentrations of $\mathrm{H}$ atoms, especially at highest initial concentrations of $\mathrm{F}$, despite the fact that (i) they may be slower at higher temperatures of the present study (in particular, reaction $7 \mathrm{~b}$ ) and (ii) $\mathrm{C}_{2} \mathrm{H}_{3}$ is rapidly consumed in disproportionation reaction 8 :

$$
\begin{aligned}
& \mathrm{C}_{2} \mathrm{H}_{3}+\mathrm{C}_{2} \mathrm{H}_{3} \rightarrow \mathrm{C}_{2} \mathrm{H}_{4}+\mathrm{C}_{2} \mathrm{H}_{2} \\
& k_{8}=1.4 \times 10^{-10} \mathrm{~cm}^{3} \text { molecule } \mathrm{s}^{-1}(\mathrm{~T}=298 \mathrm{~K})^{18}
\end{aligned}
$$

It is difficult to assess the extent of possible impact of these reactions since their rate constants at elevated temperatures are not known. However, the absence of curvature in the dependence of $[\mathrm{H}]_{\text {formed }}$ on $[\mathrm{F}]_{\text {consumed }}$ in Figure 5 and the fact that sum of the branching ratios of two reactive channels is close to 1 seem to indicate a rather limited impact of the reactions 7a and 7b. Finally, the measurements of the yields of $\mathrm{H}$-atom and HF were also performed under experimental conditions of relative measurements of the reaction rate constant at $\mathrm{T}=$ $324 \mathrm{~K}$ (section 3.1.2). The experiments consisted in titration of $\mathrm{F}$ atoms with a mixture of $\mathrm{C}_{2} \mathrm{H}_{4}$ and $\mathrm{Br}_{2}$ (i.e. in presence of $\mathrm{Br}_{2}$ in the main reactor). In this configuration, secondary 
reactions $7 \mathrm{a}$ and $7 \mathrm{~b}$ are not operative, since $\mathrm{H}$ atoms formed in reaction (1a) are rapidly transformed to $\mathrm{HBr}$ in reaction with $\mathrm{Br}_{2}$ present in the main reactor. Results of the measurements of $\mathrm{HF}$ and $\mathrm{HBr}$ monitored as a function of the fraction of $[\mathrm{F}]_{0}$ reacted with $\mathrm{C}_{2} \mathrm{H}_{4}$ are shown in Figure S8 and presented in Table 3. All branching ratio data are shown in Figure 6.

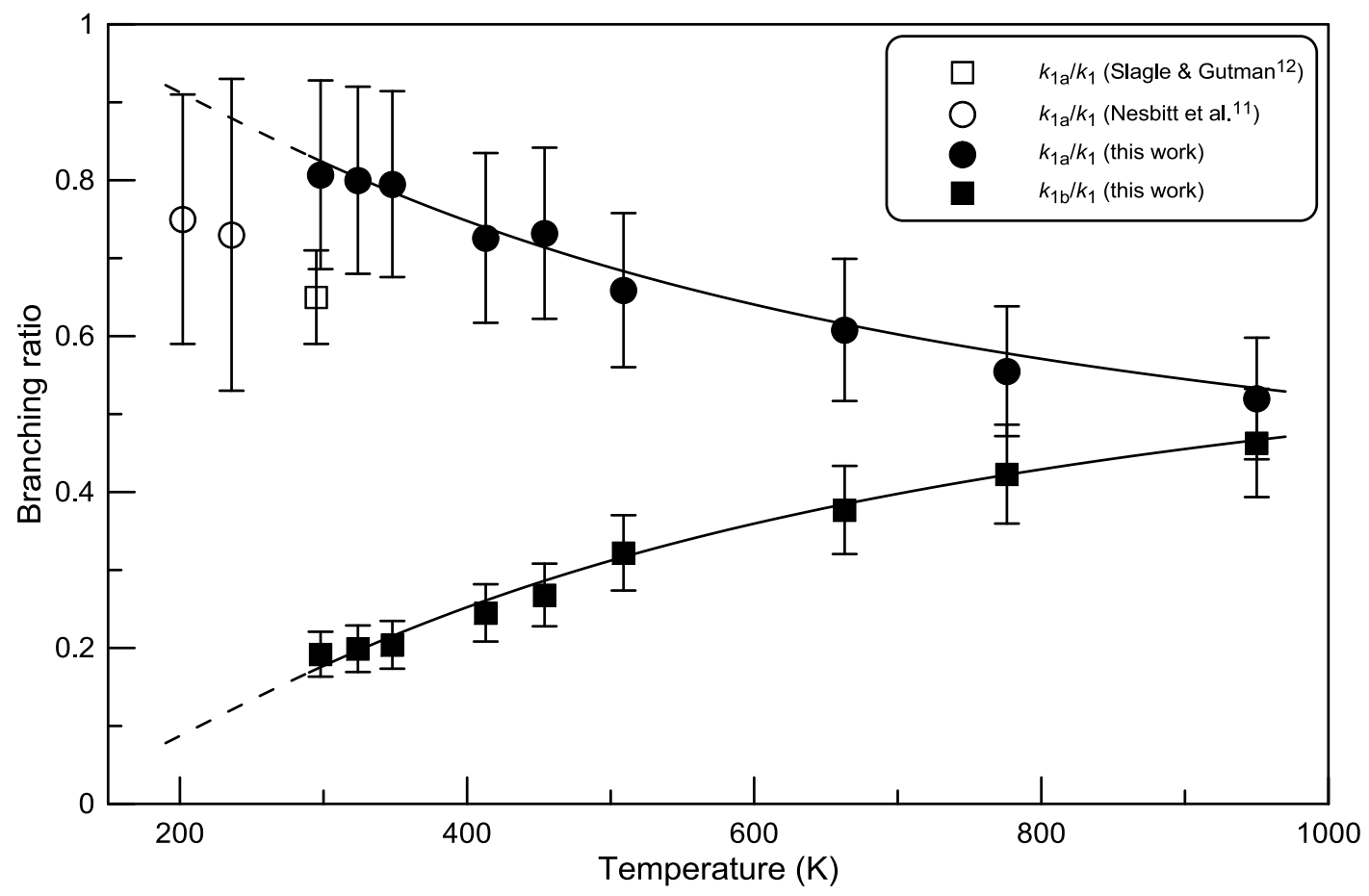

Figure 6. Reaction $\mathrm{F}+\mathrm{C}_{2} \mathrm{H}_{4}$ : summary of the branching ratio data for two reaction channels.

A trend of increase of $k_{1 \mathrm{~b}} / k_{1}\left(\mathrm{H}\right.$-atom abstraction channel) and decrease of $k_{1 \mathrm{a}} / k_{1}$ (F-atom addition / H-atom elimination channel) with increasing temperature is observed. The solid lines in Figure 6 result from a nonlinear least-squares analysis of all the branching ratio data in accordance with Arrhenius expression for $k_{1 \mathrm{~b}} / k_{1}, k_{1 \mathrm{~b}} / k_{1}=A \operatorname{xexp}(-E / \mathrm{T})$, and $k_{1 \mathrm{a}} / k_{1}=1-k_{1 \mathrm{~b}} / k_{1}$ with two variable parameters, $A$ and $E$ :

$$
\begin{aligned}
& k_{1 \mathrm{~b}} / k_{1}=(0.73 \pm 0.07) \exp (-(425 \pm 45) / \mathrm{T}) \\
& k_{1 \mathrm{a}} / k_{1}=1-(0.73 \pm 0.07) \exp (-(425 \pm 45) / \mathrm{T})
\end{aligned}
$$

with $2 \sigma$ statistical uncertainties. 
The rate constants of two channels of reaction 1 calculated using the measured branching ratio data (Table 3) and total rate constant, $k_{1}=1.78 \times 10^{-10} \mathrm{~cm}^{3}$ molecule $\mathrm{s}^{-1}$, are shown in Figure 7.

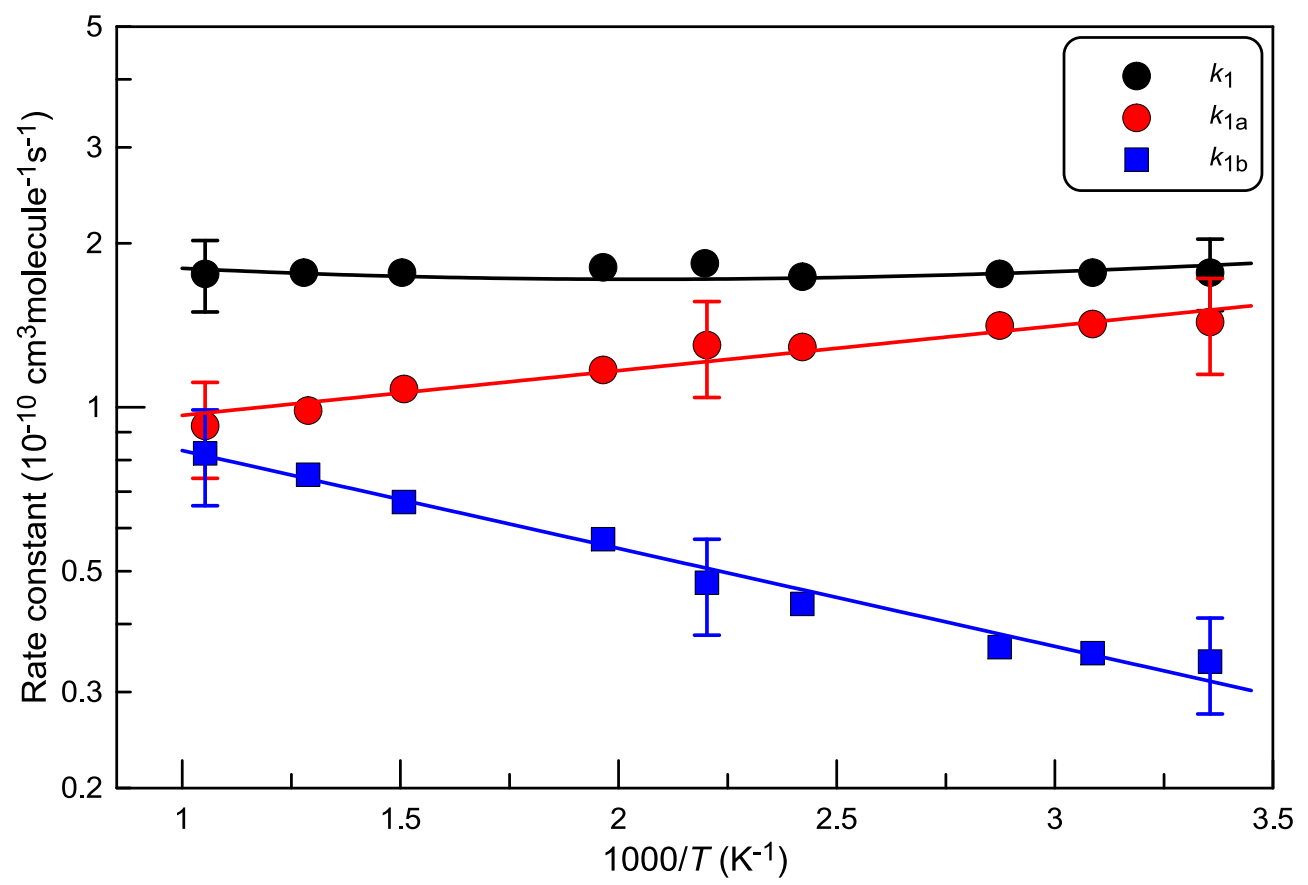

Figure 7. Total rate constant and those for two channels of reaction 1 as a function of temperature. The selectively shown error bars represent estimated $20 \%$ uncertainty on the measurements of $k_{1 \mathrm{a}}$ and $k_{1 \mathrm{~b}}$ and $15 \%$ for the total rate constant.

The solid lines result from the nonlinear least-squares analysis of all the experimental data for $k_{1 \mathrm{a}}, k_{1 \mathrm{~b}}$ and total rate constant in accordance with $k_{1}=k_{1 \mathrm{a}}+k_{1 \mathrm{~b}}$ and Arrhenius expressions for $k_{1 \mathrm{a}}$ and $k_{1 \mathrm{~b}}$ :

$$
\begin{aligned}
& k_{1 \mathrm{a}}=(0.80 \pm 0.07) \times 10^{-10} \exp (189 \pm 37 / \mathrm{T}) \mathrm{cm}^{3} \text { molecule }^{-1} \mathrm{~s}^{-1} \\
& k_{1 \mathrm{~b}}=(1.26 \pm 0.13) \times 10^{-10} \exp (-414 \pm 45 / \mathrm{T}) \mathrm{cm}^{3} \text { molecule }^{-1} \mathrm{~s}^{-1},
\end{aligned}
$$

where the uncertainties are $2 \sigma$ statistical ones. One can note that in the temperature range of the study the total rate constant can be adequately represented both by temperature independent value and sum of two Arrhenius expressions. 
3.3. Comparison with previous data. Rate constant of the reaction 1 has been measured only once using a discharge-flow reactor and electron impact ionization mass spectrometer as a detection method. ${ }^{10-11}$ The reaction rate constant was determined under pseudo-first conditions by monitoring the kinetics of $\mathrm{C}_{2} \mathrm{H}_{4}$ consumption in an excess of fluorine atoms at 1 Torr total pressure of helium and three temperatures: $\mathrm{T}=202,236$ and 298 K. These results are shown in Figure 3 in line with the present data. One can note that room temperature value of $k_{1}$ measured by Nesbitt et al. ${ }^{11}$ is by a factor of 1.7 higher than that measured in the present work. The rate constants measured in ref. 11 at two lower temperatures are in good agreement, in the range of the reported experimental uncertainties, with the present temperature independent value of $k_{1}$ extrapolated to lower temperatures (dotted line in Fig. 3). However, general trend of the increase of $k_{1}$ with temperature observed in ref. 11 is inconsistent with our observations. Reasons for this disagreement are difficult to identify, especially given that the absolute values of the rate constant from two studies are fairly consistent.

Absolute branching ratio data reported for reaction 1 in two previous studies ${ }^{11-12}$ was limited to measurements of the $\mathrm{C}_{2} \mathrm{H}_{3} \mathrm{~F}$ yield. Slagle and Gutman ${ }^{12}$ measured the branching ratio of $0.65 \pm 0.06$ for the $\mathrm{H}$-atom displacement route (1a) of the reaction $\mathrm{F}+\mathrm{C}_{2} \mathrm{H}_{4}$ at $\mathrm{T}=$ $295 \mathrm{~K}$, using pulsed-laser photolysis of $\mathrm{C}_{6} \mathrm{~F}_{5} \mathrm{Cl}$ for generation of fluorine atoms $\left(\mathrm{C}_{6} \mathrm{~F}_{5} \mathrm{Cl}(+\mathrm{h} v)\right.$ $\left.\rightarrow \mathrm{C}_{6} \mathrm{~F}_{5}+\mathrm{Cl}(+\mathrm{h} v) \rightarrow \mathrm{C}_{6} \mathrm{~F}_{4}+\mathrm{F}\right)$ and a photoionization mass spectrometry as a detection method. The authors stated $10 \%$ uncertainty on the measurements, but it seems that it could be much higher, considering that the branching ratio was determined as a ratio of $\left[\mathrm{C}_{2} \mathrm{H}_{3} \mathrm{~F}\right]$ produced in reaction 1a to consumed concentration of $\mathrm{C}_{2} \mathrm{H}_{4}$, depletion of $\mathrm{C}_{2} \mathrm{H}_{4}$ being rather low, in the range $(1.4-5.0) \%$. In any case, the yield of $\mathrm{C}_{2} \mathrm{H}_{3} \mathrm{~F}$ reported by Slagle and Gutman $^{12}$ agrees in the range of the reported uncertainties with the corresponding value of $0.81 \pm 0.12$ measured in the present study at $\mathrm{T}=298 \mathrm{~K}$ (Figure 6). Nesbitt et al. ${ }^{11}$ have 
measured the yield of $\mathrm{C}_{2} \mathrm{H}_{3} \mathrm{~F}$ under conditions of excess $\mathrm{C}_{2} \mathrm{H}_{4}$ in a discharge-flow reactor coupled to mass-spectrometric detection at a total pressure of 1 Torr and two temperatures, 202 and $236 \mathrm{~K}$. The stabilized adduct, $\mathrm{C}_{2} \mathrm{H}_{4} \mathrm{~F}$, was not detected even at lowest temperature of $202 \mathrm{~K}^{11}$ The branching ratios reported for $\mathrm{C}_{2} \mathrm{H}_{3} \mathrm{~F}$ forming channel $1 \mathrm{a}, 0.73 \pm 0.20(\mathrm{~T}=236$ $\mathrm{K})$ and $0.75 \pm 0.16(\mathrm{~T}=202 \mathrm{~K})$, are somewhat lower than those expected at these temperatures from the present data, nevertheless the results from two studies are in agreement in the range of the reported experimental uncertainties (Figure 6).

The branching ratio data from the present study can be compared also with some relative measurements available in the literature. Thus, Milstein et al. ${ }^{5}$ found that addition of F-atom to $\mathrm{C}_{2} \mathrm{H}_{4}$ is $0.83 \pm 0.02$ as rapid as addition to acetylene at about 4000 Torr total pressure. At the same time, Williams and Rowland ${ }^{19}$ reported $0.41 \pm 0.04$ for the ratio of the rate constants of $\mathrm{H}$-atom abstraction in reaction $\mathrm{F}+\mathrm{CH}_{4}$ and $\mathrm{F}$-atom addition to $\mathrm{C}_{2} \mathrm{H}_{2}$ at total pressure of nearly 3000 Torr. Combining these data and using the rate constant of $6.7 \times 10^{-11} \mathrm{~cm}^{3}$ molecule ${ }^{1} \mathrm{~S}^{-1}$ (at 298K, uncertainty factor of 1.4 ) ${ }^{13}$ for reaction of F-atom with $\mathrm{CH}_{4}$, the rate constant for addition reaction

$$
\mathrm{F}+\mathrm{C}_{2} \mathrm{H}_{4}(+\mathrm{M}) \rightarrow \mathrm{C}_{2} \mathrm{H}_{4} \mathrm{~F}(+\mathrm{M})
$$

can be calculated as $(1.35 \pm 0.5) \times 10^{-10} \mathrm{~cm}^{3}$ molecule $\mathrm{s}^{-1}$. Good agreement of this value with the rate constant measured in the present study for addition-elimination channel $k_{1 \mathrm{a}}=1.5 \times 10^{-}$ ${ }^{10} \mathrm{~cm}^{3}$ molecule $\mathrm{s}^{-1}$ (at $\mathrm{T}=298 \mathrm{~K}$ ) seems to support the assumption that the only effect of pressure in the $\mathrm{F}+\mathrm{C}_{2} \mathrm{H}_{4}$ system is on the partitioning between addition-decomposition (reaction 1a) and addition-stabilization (reaction 1c). ${ }^{11}$ It should be noted, that although we have not observed any experimental evidence for the addition-stabilization channel in the present low-pressure study, the stabilization of the adduct can be expected to compete and eventually dominate the addition-elimination process at higher pressures. Finally, concerning H-atom abstraction channel $1 \mathrm{~b}$, Smith et $\mathrm{al}^{2}$ reported the value of $0.52( \pm 15 \%)$ for the ratio 
of the rate constants of HF forming channels in reactions of $\mathrm{F}$ atoms with $\mathrm{C}_{2} \mathrm{H}_{4}$ and methane. From this data and using $k\left(\mathrm{~F}+\mathrm{CH}_{4}\right)=6.7 \times 10^{-11} \mathrm{~cm}^{3}$ molecule ${ }^{-1} \mathrm{~s}^{-1},{ }^{13}$ the rate constant of the abstraction channel $1 \mathrm{~b}$ can be calculated as $\approx 3.5 \times 10^{-11} \mathrm{~cm}^{3}$ molecule $\mathrm{e}^{-1} \mathrm{~s}^{-1}$. This value is in a good agreement with the absolute measurement of the present study, $k_{1 \mathrm{~b}}=(3.14 \pm 0.60) \times 10^{-11}$ $\mathrm{cm}^{3}$ molecule $\mathrm{s}^{-1}$ at $\mathrm{T}=298 \mathrm{~K}$.

Negative temperature dependence of the rate constant of the addition-elimination channel 1a observed in the present work indicate that addition of fluorine atom to ethylene is a barrierless process. This is in line with previous theoretical and experimental findings. Thus, according to calculations of Schlegel et al., ${ }^{20}$ the activation barrier for the addition of fluorine atom to ethylene is less than $2 \mathrm{kcal} / \mathrm{mol}$. Robinson et al. $^{7}$ in their crossed molecular beam studies of the substitution channel of reaction 1 reported that energy barrier for F-atom addition to $\mathrm{C}_{2} \mathrm{H}_{4}$ is much less than $0.8 \mathrm{kcal} \mathrm{mol}^{-1}$.

As noted in a most recent theoretical study of the reaction $\mathrm{F}+\mathrm{C}_{2} \mathrm{H}_{4}$ (where only the addition-elimination channel was considered), ${ }^{8}$ ab initio studies on the reactions involving radical addition to alkenes are very sensitive to theoretical levels and are difficult to deal with. In this respect, the experimental kinetic and mechanistic data for both $\mathrm{H}$-atom abstraction and addition-elimination channels of the reaction $\mathrm{F}+\mathrm{C}_{2} \mathrm{H}_{4}$ obtained in the present work in an extended temperature range seem to represent an interesting experimental basis for further theoretical developments.

\section{CONCLUSIONS}

In this work, we investigated the kinetics and products of the reaction of F-atoms with ethylene using a discharge flow reactor combined with an electron impact ionization mass spectrometer. The total rate constant of the reaction, $k_{1}=(1.78 \pm 0.30) \times 10^{-10} \mathrm{~cm}^{3}$ molecule $\mathrm{s}^{-1}$

1, was found to be independent of temperature in the range $298-950 \mathrm{~K}$. Three reaction 
products, $\mathrm{H}, \mathrm{C}_{2} \mathrm{H}_{3} \mathrm{~F}$ and $\mathrm{HF}$, formed in two major channels of the title reaction, $\mathrm{H}+\mathrm{C}_{2} \mathrm{H}_{3} \mathrm{~F}$ (1a) and $\mathrm{HF}+\mathrm{C}_{2} \mathrm{H}_{3}(1 \mathrm{~b})$, were identified and quantified. As a result, the rate constants for two reaction pathways, addition-elimination and $\mathrm{H}$-atom abstraction, were determined at $\mathrm{T}=298$ - $950 \mathrm{~K}$ as: $k_{1 \mathrm{a}}=(0.80 \pm 0.07) \times 10^{-10} \exp (189 \pm 37) / \mathrm{T}, k_{1 \mathrm{~b}}=(1.26 \pm 0.13) \times 10^{-10} \exp (-$ $414 \pm 45) / \mathrm{T}) \mathrm{cm}^{3}$ molecule $\mathrm{e}^{-1} \mathrm{~s}^{-1}$, respectively. The kinetic and branching ratio data obtained in the present work over an extended temperature range are in good agreement with previous absolute and relative measurements at room and lower temperatures and seem to represent an interesting experimental basis for further theoretical developments.

\section{ACKNOWLEDGEMENT}

Financial support from CNRS is gratefully acknowledged.

Supporting Information. Diagram of the flow reactor (Figure S1); examples of kinetics of Fatom consumption at different excess concentrations of $\mathrm{C}_{2} \mathrm{H}_{4}$ (Figure $\mathrm{S} 2$ ); pseudo-first order plots obtained from F- atom decays in excess of $\mathrm{C}_{2} \mathrm{H}_{4}$ at $\mathrm{T}=348$ and $413 \mathrm{~K}$ (Fig. S3) and $\mathrm{T}=$ 509 and $665 \mathrm{~K}$ (Figure S4); FBr yield from F-atom titration with $\mathrm{Br}_{2}+\mathrm{C}_{2} \mathrm{H}_{4}$ mixtures at $\mathrm{T}=$ $782 \mathrm{~K}$ (Figure S5); concentrations of $\mathrm{C}_{2} \mathrm{H}_{3} \mathrm{~F}$ and $\mathrm{HF}$ formed in reaction (1) as a function of the consumed concentration of $\mathrm{F}$ atoms at $\mathrm{T}=348$ and $663 \mathrm{~K}$ (Figure S6) and $\mathrm{T}=414$ and $950 \mathrm{~K}$ (Figure S7); concentrations of $\mathrm{H}$ atoms and HF formed in reaction (1) as a function of the consumed concentration of $\mathrm{F}$ atoms at $\mathrm{T}=324 \mathrm{~K}$ (Figure S8). 


\section{REFERENCES}

(1) Parson, J. M.; Lee, Y. T. Crossed Molecular Beam Study of $\mathrm{F}_{+} \mathrm{C}_{2} \mathrm{H}_{4}, \mathrm{C}_{2} \mathrm{D}_{4}$. J. Chem. Phys. 1972, 56, 4658-4666.

(2) Smith, D. J.; Setser, D. W.; Kim, K. C.; Bogan, D. J. HF Infrared Chemiluminescence. Relative Rate Constants for Hydrogen Abstraction from Hydrocarbons, Substituted Methanes, and Inorganic Hydrides. J. Phys. Chem. 1977, 81, 898-905.

(3) Flores, A. L.; Darwent, B. deB. Photochemical Decomposition of Nitrosyl Fluoride. J. Phys. Chem. 1969, 73, 2203-2208.

(4) Williams, R. L.; Rowland, F. S. Reactions of Fluorine-18 Atoms with Ethylene. J. Phys. Chem. 1972, 76, 3509-3517.

(5) Milstein, R.; Williams, R. L.; Rowland, F. S. Relative Reaction Rate Involving Thermal Fluorine-18 Atoms and Thermal Fluoroethyl Radicals with Oxygen, Nitric Oxide, Sulfur Dioxide, Nitrogen, Carbon Monoxide, and Hydrogen Iodide. J. Phys. Chem. 1974, 78, 857-863.

(6) Schlegel, H. B. Ab Initio Molecular Orbital Studies of Atomic Hydrogen + Ethylene and Atomic Fluorine + Ethylene. 1. Comparison of the Equilibrium Geometries, Transition Structures, and Vibrational Frequencies. J. Phys. Chem. 1982, 86, 4878-4882.

(7) Robinson, G. N.; Continetti, R. E.; Lee, Y. T. The Translational Energy Dependence of the $\mathrm{F}+\mathrm{C}_{2} \mathrm{H}_{4} \rightarrow \mathrm{H}+\mathrm{C}_{2} \mathrm{H}_{3} \mathrm{~F}$ Reaction Cross Section near Threshold. J. Chem. Phys. 1990, 92, 275-284.

(8) Zhang, M.-B.; Yang, Z.-Z. Computational Study on the Reaction $\mathrm{CH}_{2} \mathrm{CH}_{2}+\mathrm{F} \rightarrow$ $\mathrm{CH}_{2} \mathrm{CHF}+\mathrm{H} . J$. Phys. Chem. A 2005, 109, 4816-4823.

(9) Li, J.-L.; Geng, C.-Y.; Huang, X.-R.; Sun, C.-C. A Barrier-Free Atomic RadicalMolecule Reaction: F + Propene. J. Chem. Theory Comput. 2006, 2, 1551-1564.

(10) Nesbitt, F. L.; Monks, P. S.; Scanlon, M.; Stief, L. J. Absolute Rate Constants for the Reactions of $\mathrm{F}\left({ }^{2} \mathrm{P}\right)$ with $\mathrm{C}_{2} \mathrm{H}_{2}$ and $\mathrm{C}_{2} \mathrm{H}_{4}$ at $\mathrm{T}=298$ K. J. Phys. Chem. 1994, 98, 4307-4311.

(11) Nesbitt, F. L.; Thorn, R. P.; Payne, W. A.; Tardy, D. C. Absolute Rate Constant and Product Branching Fractions for the Reaction between $\mathrm{F}$ and $\mathrm{C}_{2} \mathrm{H}_{4}$ at $\mathrm{T}=202-298$ K. J. Phys. Chem. A 1999, 103, 4470-4479.

(12) Slagle, I. R.; Gutman, D. Extent of the Displacement Route in the Reactions of Fluorine Atoms with Ethylene, Vinyl Chloride, and Vinyl Bromide. J. Phys. Chem. 1983, 87, $1818-1821$. 
(13) Burkholder, J. B.; Sander, S. P.; Abbatt, J.; Barker, J. R.; Huie, R. E.; Kolb, C. E.; Kurylo, M. J.; Orkin, V. L.; Wilmouth, D. M.; Wine, P. H. Chemical Kinetics and Photochemical Data for Use in Atmospheric Studies, Evaluation No. 18, JPL Publication 1510, Jet Propulsion Laboratory. http://jpldataeval.jpl.nasa.gov (accessed January 2018).

(14) Morin, J.; Romanias, M. N.; Bedjanian, Y. Experimental Study of the Reactions of $\mathrm{OH}$ Radicals with Propane, n-Pentane, and n-Heptane over a Wide Temperature Range. Int. J. Chem. Kinet. 2015, 47, 629-637.

(15) Kaufman, F. Kinetics of Elementary Radical Reactions in the Gas Phase. J. Phys. Chem. 1984, 88, 4909-4917.

(16) Tang, M. J.; Cox, R. A.; Kalberer, M. Compilation and Evaluation of Gas Phase Diffusion Coefficients of Reactive Trace Gases in the Atmosphere: Volume 1. Inorganic Compounds. Atmos. Chem. Phys. 2014, 14, 9233-9247.

(17) Bedjanian, Y. Kinetics and Products of the Reactions of Fluorine Atoms with ClNO and $\mathrm{Br}_{2}$ from 295 to 950 K. J. Phys. Chem. A 2017, 121, 8341-8347.

(18) Baulch, D. L.; Bowman, C. T.; Cobos, C. J.; Cox, R. A.; Just, T.; Kerr, J. A.; Pilling, M. J.; Stocker, D.; Troe, J.; Tsang, W., et al. Evaluated Kinetic Data for Combustion Modeling: Supplement II. J. Phys. Chem. Ref. Data 2005, 34, 757-1397.

(19) Williams, R. L.; Rowland, F. S. Hydrogen Atom Abstraction by Fluorine Atoms. $J$. Phys. Chem. 1973, 77, 301-307.

(20) Schlegel, H. B.; Bhalla, K. C.; Hase, W. L. Ab Initio Molecular Orbital Studies of Atomic Hydrogen + Ethylene and Atomic Fluorine + Ethylene. 2. Comparison of the Energetics. J. Phys. Chem. 1982, 86, 4883-4888. 
TOC Graphic

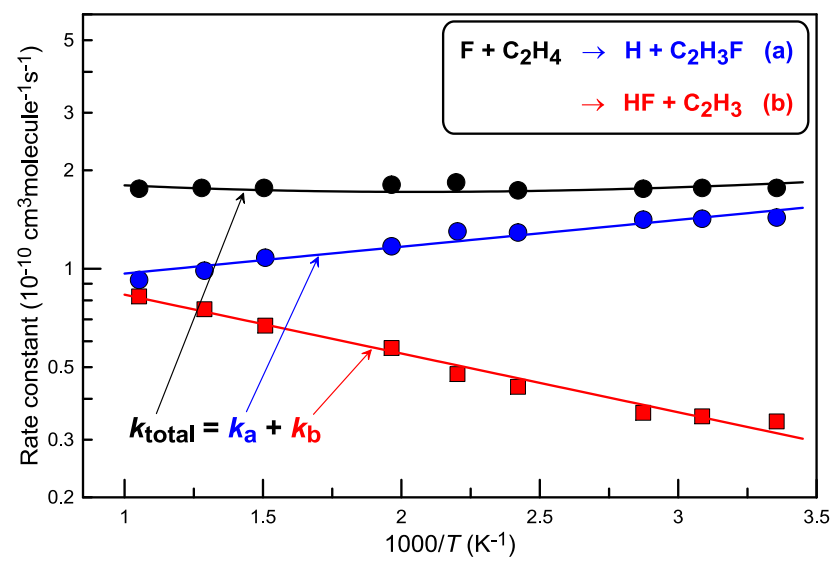

